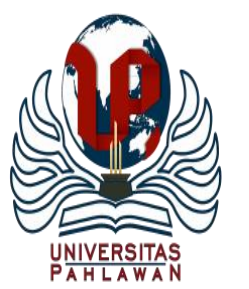

\author{
Jurnal Abdidas Volume 1 Nomor 5 Tahun 2020 Halaman 318 - 324 \\ JURNAL ABDIDAS \\ Community Development Service on Educational and Health Sciences \\ http://abdidas.org/index.php/abdidas
}

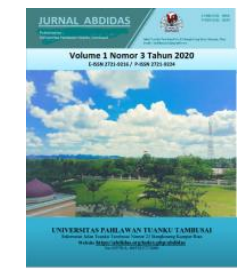

\title{
Pelatihan Peningkatan Skill Dan Pengetahuan dalam Menghadapi Tes Seleksi CPNS 2020 Di Kota Pontianak
}

\author{
Heriyanto $^{1}$, Sulaiman ${ }^{2}$ \\ Jurusan Administrasi Bisnis, Prodi DIV Administrasi Negara, Politeknik Negeri Pontianak ${ }^{1,2}$ \\ E-mail : $\underline{\text { heriyanto.radien@gmail.com }{ }^{1}} \underline{\text { imansulaiman137@yahoo.co.id }{ }^{2}}$
}

\begin{abstract}
Abstrak
Tahun 2020 ini penerimaan CPNS kembali dilaksanakan oleh pemerintah. Sebagai sebuah profesi yang di favoritkan oleh masyarakat, persiapaan yang matang tentunya perlu dilakukan dengan berbagai cara salah satunya dengan mengikuti kegiatan pelatihan pengerjaan soal serta pembekalan dari para ahli. Dalam kegiatan ini, para narasumber merupakan para ahli yang sudah berpengalaman sehingga diharapkan dapat memotivasi peserta serta menumbuhkan optimisme dalam menyambut penerimaan nanti. Pada Pengabdian Pada Masyarakat (PPM) ini, peserta akan mendapatkan trik-trik dalam menghadapi tes serta melakukan simulasi latihan pengerjaan soal-soal CAT yang telah disiapkan kemudian dilakukan evaluasi hasil pengerjaan simulasi tersebut.
\end{abstract}

Kata kunci: pelatihan, pengabdian pada masyarakat, CPNS

\begin{abstract}
In 2020 the acceptance of CPNS is again carried out by the government. As a profession that is favored by the community, thorough preparation certainly needs to be done in various ways, one of which is by taking part in question-processing training and debriefing from experts. In this activity, the speakers are experienced experts so that they are expected to motivate the participants and foster optimism in welcoming the reception later. In Community Service PPM, participants will get tricks in facing the test and carry out the training simulation for the preparation of the CAT questions that has been prepared then evaluate the results of the simulation work Keywords: training, community service, CPNS
\end{abstract}

Copyright (c) 2020 Heriyanto, Sulaiman

$\square$ Corresponding author

Address : Politeknik Negeri Pontianak

Email : Heriyanto.radien@gmail.com

ISSN 2721-9224 (Media Cetak)

Phone : 085215277682

ISSN 2721-9216 (Media Online)

DOI : https://doi.org/10.31004/abdidas.v1i5.65 


\section{PENDAHULUAN}

Sejak dicabutnya moratorium penerimaan ASN pada tahun 2017 yang lalu, Masyarakat Indonesia bisa sedikit bernafas lega. Moratorium yang dilakukan ini menjadi momok yang cukup menghawatirkan para pencari kerja. Dengan adanya moratorium atau kebijakan pemberhentian sementara penerimaan ASN, profesi ini sementara waktu seolah-olah tertutup untuk dimasuki. Mengingat tujuan moratorium yaitu penataan ulang birokrasi, memperbaiki birokrasi yang terkesan tidak efektif dan efesien. Berdasarkan data Badan Pusat Statistik (BPS) per Februari 2019, jumlah pengangguran secara nasional masih tergolong tinggi, yakni 6,87 juta penduduk (www.bps.go.id, 2019). Jumlah pengangguran yang cukup besar ini perlu segera di distribusikan ke dalam dunia kerja, salah satu profesi yang tersedia yaitu menjadi ASN.

Aparatur sipil negara (ASN) sampai saat ini, merupakan salah satu profesi yang sangat diminati oleh masyarakat Indonesia. Gaji pokok di atas Upah Minimum Regional (UMR), tingginya tingkat kinerja di bebarapa lembaga pemerintah, serta jaminan hari tua (pensiun) membuat masyarakat antusias dalam mengikuti tahapan seleksi penerimaan ASN tersebut. Pada tahun 2018 yang lalu, pemerintah membuka lowongan sebesar, 238.015 formasi, sedangkan jumlah peserta yang mendaftar mencapai 2,4 juta, sebuah minat yang tinggi yang ditunjukkan masyarakat. Sehingga sekitar 2,3 juta lebih peserta yang harus gugur/ gagal dalam mencapai harapan mereka untuk berkarir dalam profesi ini. Pada pelaksanaan pengadaan tahun 2018 lalu, tes CPNS menggunakan CAT dengan nilai Passing Grade yang sangat tinggi sehingga banyak peserta CPNS yang tidak lolos TKD.

Tahun 2020 ini, pemerintah kembali akan membuka penerimaan CPNS yang merupakan angin segar bagi pencari kerja ataupun masyarakat yang tertarik dengan profesi ini. Namun demikian, untuk menjadi seorang ASN bukan merupakan hal yang mudah, harus melewati berbagai tahapan seleksi. Para peserta tes harus melalui tahapan tes yang panjang dan saringan yang ketat dari seleksi administrasi, CAT, SKB hingga tahapan pengumuman. Penerimaan CPNS tahun 2020 ini merupakan peluang yang seharusnya dimanfaatkan secara maksimal sehingga dapat lulus salah satunya dengan pembekalan dan persiapan yang matang melalui pelatihan khusus pengerjaan soal CPNS 2020 agar peserta CPNS bisa lebih siap menghadapi tes pengadaan CPNS 2020.

Penerimaan PNS terdiri dari berbagai tahapan, mulai dari pengumuman penerimaan, seleksi administrasi hingga pengumuman kelulusan merupakan tahapan yang panjang. Tahapan ini perlu dipersiapkan secara maksimal agar tidak melakukan kesalahan yang merugikan. Selain itu kompetisi yang ketat secara nasional untuk menjadi CPNS, memerlukan wawasan, skill dan trik-trik dalam pengerjaan soal serta pengetahuan yang cukup agar dapat lulus pada berbagai tahapan seleksi yang ada. Sehingga pelatihan dan pembekalan ini dimaksudkan sebagai bagian dari persiapan masyarakat (pencari kerja) khususnya di kota Pontianak dalam menyambut penerimaan CPNS 2020 ini. 
Tujuan yang ingin dicapai dari kegiatan pengabdian kepada masyarakat ini secara umum adalah sebagai berikut:

1. Kegiatan PKM diharapkan dapat menimbulkan optimisme bagi masyarakat Kota Pontianak yang memiliki rencana berpartisipasi dalam tes CPNS 2020 yang akan dibuka nanti.

2. Memberikan informasi yang bermanfaat kepada peserta pelatihan yang terkait pelaksanaan tes CPNS 2020. Meningkatkan keterampilan peserta dalam pengerjaan soal-soal tes CAT. Sedangkan manfaat kegiatan PKM yang dilakukan diantaranya sebagi berikut.

3. Program pengabdian pada masyarakat yang dilakukan oleh tim dosen Politeknik Negeri Pontianak merupakan upaya yang dilaksanakan dalam rangka mendukung program pemerintah tentang pengadaan calon pegawai negeri sipil di Kota Pontianak.

4. Meningkatkan kesiapan masyarakat Kota Pontianak dalam aspek mental, pengetahuan dan keterampilan dalam rangka persiapan menghadapi tes CPNS yang akan dilaksanakan.

\section{TINJAUAN PUSTAKA}

\section{Definisi Pelatihan}

Pelatihan merupakan proses membantu para tenaga kerja untuk memperoleh afektivitas dalam pekerjaan mereka yang sekarang atau yang akan datang melalui pengembangan kebiasaan tentang pikiran, tindakan, kecakapan, pengetahuan, dan sikap yang layak (Sastrohadiwiryo, 2001). Sedangkan menurut Rivai (2010), pelatihan adalah proses secara sistematis mengubah tingkah laku pegawai untuk mencapai tujuan organisasi.
Pelatihan berkaitan dengan keahlian dan kemampuan pegawai untuk melaksanakan pekerjaan saat ini. Pelatihan memiliki orientasi saat ini dan membantu pegawai untuk mencapai keahlian dan kemampuan tertentu agar berhasil dalam melaksanakan pekerjaannya. Berdasarkan pengertian di atas maka penulis menyimpulkan pelatihan adalah suatu kegiatan yang positif yang dilaksanakan dengan tujuan untuk meningkatkan pengetahuan serta keterampilan dan sikap yang dibutuhkan tenaga kerja/ calon tenaga kerja tersebut.

\section{Tujuan Pelatihan}

Pelatihan merupakan aktifitas yang harus dilaksanakan secara sistematis agar memberikan dampak positif. Tujuan pelatihan menurut Mangkunegara \& Prabu (2010:52) yaitu:

1. Meningkatkan penghayatan jiwa dan ideologi

2. Meningkatkan produktivitas kerja

3. Meningkatkan kualitas kerja

4. Meningkatkan ketetapan perencanaan sumber daya manusia

5. Meningkatkan sikap moral dan semangat kerja.

6. Meningkatkan rangsangan agar pegawai mampu berprestasi secara maksimal

Sedangkan menurut Sedarmayanti (2010:170) adalah menambah pengetahuan, keterampilan dan sikap berdasarkan tujuan-tujuan pelatihan diatas, dapat ditarik kesimpulan bahwa pelatihan yang dilakukan berdampak positif yakni dapat meningkatkan kapasitas peserta pelatihan dalam berbagai aspek sesuai dengan pelatihan yang diikuti. 


\section{Definisi Pegawai Negeri Sipil}

Menurut (Hasibuan, 2005:41) pegawai adalah seseorang pekerja yang bekerja di Bawah perintah orang lain dan menerima balas jasa yang besarnya tertentu.

Menurut Kranenburg Pegawai Negeri yaitu pejabat yang ditunjuk, jadi pengertian tersebut tidak termasuk terhadap mereka yang memangku jabatan meakili seperti anggota parlemen, presiden dan sebagainya (Hartini, dkk., 2008:31)

Pegawai Negeri Sipil yang selanjutnya disingkat PNS bukan saja unsur aparatur negara, tetapi juga abdi masyarakat yang hidup di tengahtengah masyarakat dan bekerja untuk kepentingan masyarakat. Kedudukan dan peranan dari Pegawai Negeri dalam setiap organisasi pemerintah sangatlah menentukan, sebab Pegawai Negeri Sipil merupakan tulang punggung pemerintahan dalam melakukan pembangunan nasional (Hartini, dkk., 2008:31).

\section{Tahapan Pengadaan CPNS}

Adapun tata cara pengadaan pegawai negeri ditentukan dalam Peraturan Pemerintah Nomor 98 Tahun 2000 (Tentang Pengadaan Pegawai Negeri Sipil) dalam pasal 2 ayat 1 yaitu pengadaan pegawai negeri dilakukan mulai dari perencanaan pengumuman, pelamaran, penyaringan, pengangkatan calon Pegawai Negeri Sipil sampai dengan pengangkatan menjadi pegawai negeri sipil. Dengan mengacu pada peraturan pemerintah, maka penulis menguraikan tahapan proses pengadaan calon Pegawai Negeri Sipil, sebagai berikut:
1. Perencanaan kebutuhan pegawai

2. Pengumuman

3. Pelamaran

4. Penyaringan/seleksi

5. Pengangkatan calon Pegawai Negeri Sipil

\section{METODE}

\section{Kerangka Pemecahan Masalah}

Dalam pelaksanaan kegiatan PKM ini, Tim PKM melakukan berbagai studi literasi dari berbagai buku serta media untuk menemukan kebutuhan masyarakat Kota Pontianak, selain itu juga melakukan interview dengan masyarakat dalam rangka merumuskan kegiatan pelatihan ini.

\section{Realisasi Pemecahan Masalah}

Program Pengabdian pada Masyarakat yang dilakukan oleh Tim Dosen Politeknik Negeri Pontianak merupakan upaya yang dilaksanakan dalam rangka mendukung program pemerintah dalam pengadaan calon Pegawai Negeri Sipil di Kota Pontianak tahun 2020.

\section{Khalayak Sasaran}

Program pengabdian pada masyarakat yang dilakukan oleh Tim Dosen Politeknik Negeri Pontianak merupakan upaya positif yang perlu dilaksanakan dalam rangka mendukung program pemerintah tentang dalam pengadaan calon Pegawai Negeri Sipil di Kota Pontianak. Sasaran pelatihan pengerjaan soal CPNS 2020 dalam program pengabdian masyarakat ini adalah masyarakat Kota Pontianak. 


\section{Metode yang digunakan.}

Metode pelaksanaan pelatihan dilakukan sesuai dengan kebutuhan peserta dengan menggunakan metode yang mudah diterapkan agar dapat memberikan dampak positif bagi peserta selama mengikuti tes. Dalam pelaksanaan kegiatan ini dilakukan dengan berbagai metode yaitu sebagai berikut:

1. Penyampaian informasi oleh pemateri

2. Tanya jawab (dialog) dengan peserta

3. Simulasi pelaksanaan pelatihan pengerjaan soal melalui bedah soal-soal CPNS 2020

4. Evaluasi terhadap soal yang telah dikerjakan oleh peserta

\section{HASIL DAN PEMBAHASAN}

Pelaksanaan kegiatan pelatihan simulasi dan pendampingan dimaksudkan agar dapat meningkatkan persentase kelulusan pada seleksi CPNS pada tahun 2020 untuk warga sekitar kampus. Pelatihan ini diikuti oleh warga yang berada disekitar kampus politeknik negeri Pontianak, dimana pelatihan ini dihadiri oleh 40 orang peserta.

SKD kepanjangan dari Seleksi Kompetensi Dasar. SKD adalah salah satu tes untuk melamar jadi CPNS dan Sekolah Kedinasan ketika peserta akan menjadi seorang PNS yang diadakan oleh BKN atau Badan Kepegawaian Negara (www.bkn.go.id, 2020). Tujuan dari tes ini adalah untuk menguji kemampuan dan karakteristik peserta yang berupa ilmu pengetahuan, keterampilan dan perilaku yang mencerminkan ciri-ciri jadi PNS/ASN di Indonesia.
Menurut Permen PAN-RB Nomor 23 Tahun 2019 (Kriteria Penetapan Kebutuhan Pegawai Negeri Sipil dan Pelaksanaan Seleksi Calon Pegawai Negeri Sipil), Kompetensi Dasar adalah kemampuan dan karakteristik dalam diri seseorang berupa pengetahuan, ketrampilan dan perilaku yang menjadi ciri-ciri seorang PNS RI. SKD sendiri beda dengan tes lainnya, karena SKD dilaksanakan menggunakan Computer Assited Tes (CAT). Sehingga peserta akan menjawab soal-soal menggunakan komputer. Segala perlengkapan tes telah disediakan oleh BKN sendiri, jadi peserta tinggal mengerjakan soal saja.

\section{Jenis Soal SKD}

Soal SKD terdiri dari 100 soal yang harus peserta kerjakan dalam waktu 90 menit. Yang artinya peserta hanya punya waktu kurang lebih 1 menit untuk menjawab setiap soalnya.

Dari hasil pengabdian kepada masyarakat yang dilakukan di Aula Galaherang Asrama Mahasiswa Kabupaten Mempawah, peserta mendapatkan trik dan tips dalam mengerjakan soal-soal tes CPNS tgan cepat dan tepat. Selain itu, peserta pelatihan memperoleh hasil antara lain: ke100 Soal SKD tersebut terdiri dari 3 kategori soal atau 3 sub tes, yaitu Tes Wawasan Kebangsaan (TWK), Tes Intelegensia Umum (TIU) \& Tes Karakteristik Pribadi (TKP).

\section{Tes Wawasan Kebangsaan (TWK) \\ Peserta memiliki pengetahuan dan pemahaman baru tentang soal-soal wawasan kebangsaan. Tes Wawasan Kebangsaan, merupakan subtes yang menguji pengetahuan}


wawasan kebangsaan peserta seperti pengetahuan sejarah perjuangan bangsa, UUD 1945, dan lainlain. TWK terdiri dari 30 soal dengan passing grade 65. Ketentuan skor TWK adalah jawaban benar bernilai 5 dan jawaban salah bernilai 0 .

\section{Tes Intelegensia Umum (TIU)}

Peserta memiliki pengetahuan dan pemahaman baru tentang soal-soal intelegasi umum. Tes Intelegensi Umum, merupakan subtes yang menguji kemampuan intelegensi peserta, soalnya berupa perhitungan matematika, logika, dll. TIU terdiri dari 35 soal dengan passing grade 80. Ketentuan skor TIU adalah jawaban benar bernilai 5 dan jawaban salah bernilai 0 .

\section{Tes Kepribadian Pribadi (TKP)}

Peserta memiliki pengetahuan dan pemahaman baru tentang soal-soal Kompetensi Kepribadian. Tes Karakteristik Pribadi, merupakan subtes yang menguji karakteristik kepribadian peserta, soalnya berupa soal-soal kepribadian. TKP terdiri dari 35 soal dengan passing grade 126. Ketentuan skor TKP adalah jawaban terbaik bernilai 5 dan jawaban terendah bernilai 1, tidak menjawab bernilai 0 . Nah itu dia 100 soal SKD, tapi tahukah peserta dalam tes ini tidak seperti tes biasanya, bukan soal akumulatif, seperti yang dijelaskan diatas, disetiap kategori soal terdapat ketentuan skor minimal atau biasa disebut dengan Passing Grade.

\section{Passing Grade SKD}

Passing Grade adalah sebuah nilai minimal yang harus dipenuhi oleh peserta agar bisa lulus.
Setiap kategori soal SKD memiliki Passing Grade masing-masing. Passing grade ini diberlakukan oleh Permen PAN-RB dan passing grade ini akan berbeda-beda setiap tahun tergantung dari kebijakan PAN-RB sendiri. Berikut adalah passing grade SKD berdasarkan Permen PAN-RB No 23 Tahun 2020:

- Tes Wawasan Kebangsaan $($ TWK $)=65$

- Tes Intelegensia Umum (TIU) $=80$

- Tes Karakteristik Pribadi $(\mathrm{TKP})=126$

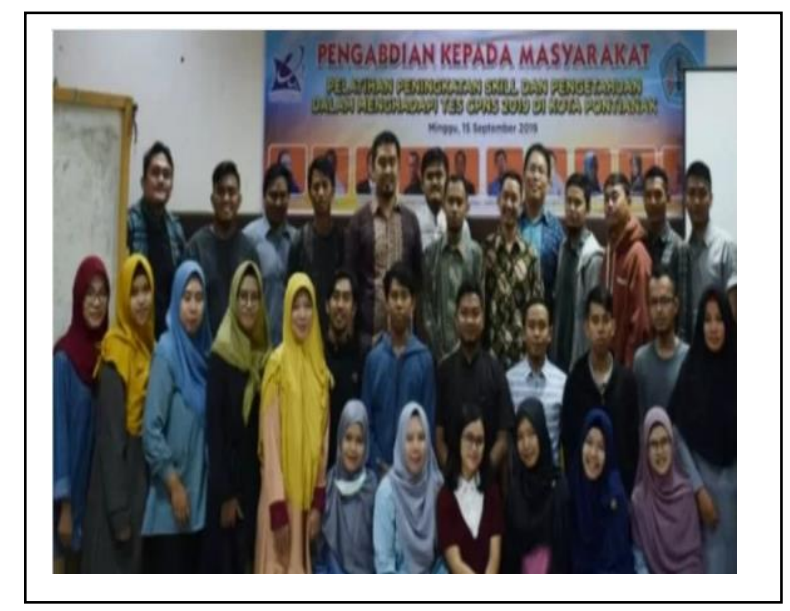

Gambar 1. Pelatihan Peningkatan Skill Dan Pengetahuan Dalam Menghadapi Tes Seleksi Cpns 2020 Dikota Pontianak

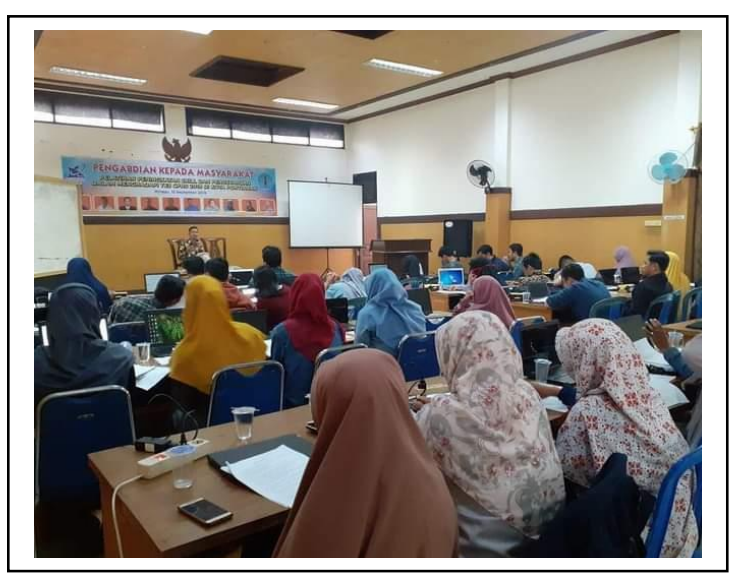

Gambar 2. Pelatihan Peningkatan Skill Dan Pengetahuan Dalam Menghadapi Tes Seleksi Cpns 2020 Dikota Pontianak 


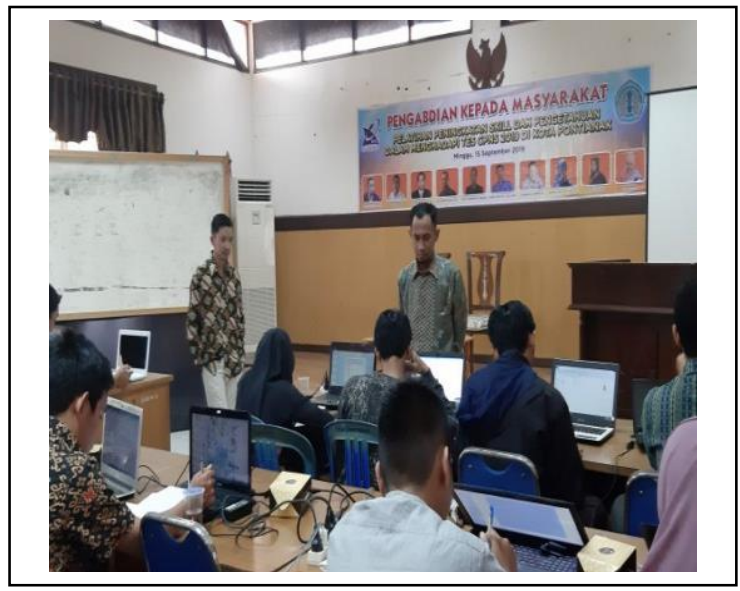

Gambar 3. Pelatihan Peningkatan Skill Dan Pengetahuan Dalam Menghadapi Tes Seleksi Cpns 2020 Dikota Pontianak

\section{SIMPULAN}

Dari hasil kegiatan pengabdian kepada masyarakat oleh tim, dapat diambil beberapa kesimpulan sebagai berikut:

1. Peserta mendapatkan pengetahuan dan pemahaman baru tentang soal-soal wawasan kebangsaan

2. Peserta mendapatkan pengetahuan dan pemahaman baru tentang soal-soal kompetensi pribadi

3. Peserta mendapatkan trik dan tips mengerjakan soal-soal CPNS dengan cepat dan tepat

Diharapkan dengan adanya kegiatan pelatihan ini bertambahnya pengetahuan dan wawasan tentang kebangsaan, intelegensi umum, dan kompetensi pribadi sehingga dapat menghadapi tes CPNS 2020 nanti dengan penuh percaya diri dan mendapatkan hasil yang memuaskan.

\section{DAFTAR PUSTAKA}

Hartini, S., Kadarsih, S., \& Sudrajat, T. (2008). Hukum Kepegawaian di Indonesia. Jakarta: Sinar Grafika.

Hasibuan, M. S. P. (2005). Manajemen Sumber Daya Manusia Edisi Revisi. Jakarta: Bumi Aksara.

Mangkunegara, A. P., \& Prabu, A. (2010). Manajemen Sumber Daya Manusia. Bandung: PT. Remaja Rosdakarya.

Peraturan Pemerintah Nomor 98 Tahun 2000. Tentang Pengadaan Pegawai Negeri Sipil. Biro Peraturan Perundang-undangan RI.

Permenpan RB Nomor 23 Tahun 2019, Kriteria Penetapan Kebutuhan Pegawai Negeri Sipil (PNS) dan Pelaksanaan Seleksi Calon Pegawai Negeri Sipil (CPNS) Tahun 2019, Kementerian Pendayagunaan Aparatur Negara dan Reformasi Birokrasi.

Rivai, Z. V. (2010). Manajemen Sumber Daya Manusia untuk Perusahaan dari Teori ke Praktik. Jakarta: Raja Grafindo.

Sastrohadiwiryo, B. S. (2001). Manajemen Tenaga Kerja Indonesia. Jakarta: Bumi Aksara.

Sedarmayanti. (2010). Sumber Daya Manusia dan Produktivitas Kerja, cetakan kedua. Bandung: PT. Mandar Maju.

Www.bkn.go.id. (2020). Pembahasan Soal SKB CPNS 2019. Humas Badan Kepegawaian Negara. [http://www.bkn.go.id/berita/bkngelar-rapat-pembahasan-soal-skb-cpns-2019].

Www.bps.go.id. (2019). Tingkat Pengangguran Terbuka (TPT) sebesar 5,01 persen. Laman Web Badan Pusat Statistik. [http://www.bps. go.id/pressrelease/2019/05/06/1564/Februari2019-tingkat-pengangguran-terbuka-tptsebesar-5-01-persen.html]. 